\title{
edoc
}

Institutional Repository of the University of Basel

University Library

Schoenbeinstrasse 18-20

CH-4056 Basel, Switzerland

http://edoc.unibas.ch/

Year: 2008

\section{Assessment of the stability of TGF 33 bioactivity for potential bioreactor applications}

Vonwil, D. and Wendt, D. and Stroebel, S. and Wallny, H. J. and Gygax, D. and Heberer, M. and Martin, I.

Posted at edoc, University of Basel

Official URL: http://edoc.unibas.ch/dok/A5248829

Originally published as:

Vonwil, D. and Wendt, D. and Stroebel, S. and Wallny, H. J. and Gygax, D. and Heberer, M. and Martin, I.. (2008) Assessment of the stability of TGF 3 bioactivity for potential bioreactor applications. Biochemical engineering journal, Vol. 3. S. 586-589.

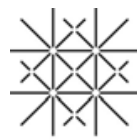




\section{Assessment of the stability of TGF- $\beta 3$ bioactivity}

\section{for potential bioreactor applications}

D. Vonwil ${ }^{\mathrm{a}}$, D. Wendt ${ }^{\mathrm{a}}$, S. Ströbel ${ }^{\mathrm{a}}$, H. J. Wallny ${ }^{\mathrm{b}}$, D. Gygax ${ }^{\mathrm{c}}, \mathrm{M}$.

Heberer $^{\mathrm{a}}$, I. Martin ${ }^{\mathrm{a},{ }^{*}}$

a Departments of Surgery and of Research, University Hospital Basel, Switzerland

${ }^{\mathrm{b}}$ Novartis Pharma AG, Biotechnology Development, Switzerland

${ }^{\mathrm{c}}$ University of Applied Sciences Northwestern Switzerland

*To whom correspondence should be addressed:

Ivan Martin

Institute for Surgical Research and Management

Hebelstrasse 20, 4031 Basel, Switzerland

Telefone: +41 61265 2384, fax: +41 61265 3990, e-mail:

imartin@uhbs.ch 


\begin{abstract}
In order to develop suitable bioreactor systems and processes for automated and standardized cell cultures involving the use of bioactive factors, we determined the stability of TGF $\beta 3$ over storage time and under conditions typically used for mammalian cell culture. Using a reporter gene assay with firefly luciferase as readout, significant reduction of TGF $\beta 3$ bioactivity was detected to occur both in serum containing (SCM) and serum free medium (SFM). The residual activity, quantified by parallel line assays, progressively decreased with time, down to $60 \%$ in SCM and $84 \%$ in SFM after one week at $37^{\circ} \mathrm{C}$, with no further decrease until three weeks, whereas such loss could not be predicted using a conventional ELISA method. The reduction of TGF $\beta 3$ bioactivity had a negligible influence in a typical biological assay (e.g., chondrocyte proliferation), supporting the possibility of prolonged storage of medium pre-supplemented with TGF $\beta 3$ for bioreactor-based chondrocyte expansion. With the ultimate goal of defining suitable operating protocols for automated cell culture bioreactors, the proposed approach should be extended to assessing the stability of other possibly labile medium supplements.
\end{abstract}

Keywords (6) : growth factor, tissue engineering, bioassay, automation, standardization, bioprocess. 


\section{Introduction}

Bioreactor systems offer a large potential to introduce automation and standardization in cell and tissue culture, which are key functions for reproducible laboratory practice and, prospectively, for effective and safe translation of cell-based therapies in the clinic [1]. With regard to automation and simplification of liquid handling, the use of culture medium already including the required bioactive supplements (e.g., growth factors, vitamins) would be technically desirable as compared to having the different components stored at different temperatures/compartments. With regard to standardization, however, storing a fully supplemented medium at specific conditions, ready for being dispensed to the culture, raises the question of whether and to which extent the bioactivity of its components is stable over time.

Transforming growth factor beta 3 (TGF $\beta 3$ ) is widely used as culture supplement as it is known to regulate proliferation, differentiation, migration and survival of a large variety of mammalian cells during in vitro culture [2]. Among other functions, TGF $\beta 3$ is an important modulator of the hematopoietic and immune system [3], and plays an important role in the chondrogenic differentiation of mesenchymal stem cells [4] and in the expansion and redifferentiation of articular chondrocytes $[5,6]$.

In this paper, we aimed at determining the stability of TGF $\beta 3$ over storage time, under conditions commonly used for mammalian cell culture. A specific and sensitive reporter gene assay using firefly luciferase as readout [7], which recognizes only biologically active molecules, was used to quantify TGF 33 bioactivity. Results were 
compared with measurements based on a conventional enzyme linked immunosorbent assay (ELISA) method, and associated to the functional performance of the molecule in chondrocyte cultures.

\section{Materials and Methods}

\section{$\underline{\text { Storage conditions for TGF } \beta 3 \text { solutions }}$}

Stock solutions of $10 \mu \mathrm{g} / \mathrm{ml}$ recombinant human TGFß3 (R\&D, UK), reconstituted in phosphate-buffered saline, 4mM hydrochloric acid, and $1 \mathrm{mg} / \mathrm{ml}$ human serum albumin, were stored for up to 21 days at a temperature of either $25{ }^{\circ} \mathrm{C}$ or $37^{\circ} \mathrm{C}$ in aliquots of $1 \mathrm{ml}$ in cryotubes (Greiner bioone, Switzerland; polypropylene). The $\mathrm{pH}$ remained constant at 8.1. Storage media consisted of Dulbecco’s Modified Eagle’s Medium (DMEM, Gibco, UK) with final concentrations of $10 \%$ fetal bovine serum (FBS, Gibco, UK), $100 \mathrm{U} / \mathrm{ml}$ penicillin $+100 \mu \mathrm{g} / \mathrm{ml}$ streptomycin $+0.29 \mathrm{mg} / \mathrm{ml} \mathrm{L-glutamine} \mathrm{(Gibco,} \mathrm{UK),} 100 \mathrm{mM}$ HEPES (Gibco, UK), $1 \mathrm{mM}$ sodium pyruvate (Gibco, UK), $0.1 \mathrm{mM}$ ascorbic acid 2-phosphate (Sigma Chemical, USA) and $10 \mu \mathrm{g} / \mathrm{ml}$ human insulin (Novo Nordisk, Denmark) [6] (serum containing medium, SCM), or as a

substitute of FBS, ITS $^{+1}$ (Sigma Chemical, St. Louis; i.e., $10 \mu \mathrm{g} / \mathrm{ml}$ insulin, $5.5 \mathrm{mg} / \mathrm{ml}$ transferrin, $5 \mathrm{ng} / \mathrm{ml}$ selenium, $0.5 \mathrm{mg} / \mathrm{ml}$ bovine serum albumin, $4.7 \mathrm{mg} / \mathrm{ml}$ linoleic acid) and $0.01 \mathrm{mM}$ dexamethasone (Sigma Chemical, USA) [4] were added (serum free medium, SFM). 


\section{$\underline{\text { Luciferase assays }}$}

The bioactivity of TGF $\beta 3$ was assessed using mink lung epithelial cells (tMLEC 32), transfected with a construct containing a luciferase gene from fireflies and inserted under the PAI-1 promoter, as previously described [7] (Fig. 1). Briefly, cells were seeded at the density of $4 * 10^{4}$ cells/well in white 96-well plates (Becton Dickinson, France). After the cells were allowed to attach for 4h, culture medium was replaced with 50 $\mu 1$ of DMEM w/o phenol red (Gibco, UK), containing PSG and $1 \mathrm{mg} / \mathrm{ml}$ bovine serum albumin (Sigma Cell, USA). To determine the bioactivity of the stored sample relative to a freshly thawed standard, a dilution series was prepared to match the luciferase assay working range. For each condition, the dilution was prepared in quadruplicates. From this dilution plate, aliquots of $50 \mu$ were transferred to the previously prepared assay plate and incubated for $14 \mathrm{~h}$ at $37^{\circ} \mathrm{C} / 5 \% \mathrm{CO}_{2}$. Next, 100 $\mu 1$ of SteadyGlo ${ }^{\mathrm{TM}}$ luciferase assay kit (Promega) were added to each well of the 96 well plate. The luciferase activity was measured at $20^{\circ} \mathrm{C}$ by a Topcount luminometer (Perkin Elmer, USA) with an integration time of 2s/well, and reported as counts per second.

\section{$\underline{\text { ELISA assays }}$}

Levels of TGF $\beta 3$ were also determined by a commercial ELISA kit (R\&D Systems, Minneapolis, MN, USA), according to the manufacturer's instructions. The samples stored at $37^{\circ} \mathrm{C}$ for up to 21 days were assayed with reference to standard curves generated using human recombinant TGFß3 (R\&D Systems, Minneapolis, MN, USA). 


\section{Quantification of Relative Bioactivity}

Since the luciferase assay has relatively high inherent variability, the residual bioactivity of a stored TGF $\beta 3$ aliquot was derived by measuring the shift of its dilution curve from the standard curve. For this purpose, lines were fitted through three consecutive dose points of the dilution curves, using a parallel-line assay program (Stegmann Systemberatung, Germany) (Fig. 2A). The concentration range wherein the criteria for slope and parallelity were fulfilled was found to be between 0.08 to $0.625 \mathrm{ng} / \mathrm{ml}$ TGF $\beta 3$. Thus, experimental samples were diluted accordingly.

\section{$\underline{\text { Proliferation assays }}$}

The biological effect of stored TGF $\beta 3$ was tested in chondrocyte proliferation assays, considering its marked effect when used in conjunction with Fibroblast Growth Factor (FGF)-2 [5]. Human articular chondrocytes were obtained after informed patient's consent, following study protocol approval by the local ethical committee (Nr. 78/07), and cultured as previously published [5]. After the first passage in SCM, cells were seeded into tissue culture treated 96-well plates at a density of $2 * 10^{3}$ cells/well, in $100 \mu \mathrm{l}$ of medium. After $30 \mathrm{~h}$, medium was supplemented with $5 \mathrm{ng} / \mathrm{ml} \mathrm{FGF-2} \mathrm{and} \mathrm{an} \mathrm{intended} \mathrm{concentration} \mathrm{of} 1$ ng/ml TGF $\beta 3$ (for stored samples). After 4 days, cells were pulsed with 3H-thymidine (1 mCi well, Amersham, UK) for 18 hours, harvested and the incorporated radioactivity was counted on a Top count reader (Perkin Elmer, USA). 
Differences between groups in luciferase, ELISA and proliferation assays were assessed by ANOVA with Tukey's posthoc tests, and considered statistically significant if $\mathrm{p}<0.05$.

\section{Results and discussion}

Initially, SCM containing $10 \mathrm{ng} / \mathrm{ml}$ TGF $\beta 3$ was stored at $25^{\circ} \mathrm{C}$ or $37^{\circ} \mathrm{C}$ for 1,6 and 24 hours. The luciferase assay showed that at either temperature the bioactivity of TGF $\beta 3$ was unaltered after 1 hour, but after 24 hours it was reduced to $89 \%$ at $25^{\circ} \mathrm{C}$ and down to $88 \%$ at $37^{\circ} \mathrm{C}$. As there was no substantial difference between the two temperature conditions, further experiments were all performed at $37^{\circ} \mathrm{C}$.

In a second experimental setup, aliquots of SCM or SFM containing $10 \mathrm{ng} / \mathrm{ml} \mathrm{TGF} \beta 3$ were stored at $37^{\circ} \mathrm{C}$ for $1,3,7$ and 21 days. The first significant reduction of the initial bioactivity was detected after 3 days in SCM $(p=0.0011)$ or SFM $(p=0.0026)$. The residual bioactivity of TGF $\beta 3$ was significantly reduced over time $(p=2.7 \mathrm{E}-07)$, with a progressive loss down to $60 \%(\mathrm{p}=0.0150)$ in SCM and down to 84\% ( $=0.0003)$ in SFM after 1 week (Fig. 2B). Worthy of note, the residual bioactivity was not further decreased between 7 and 21 days, but remained at 63\% in SCM and 73\% in SFM.

In order to confirm the loss of activity of TGF $\beta 3$, stored aliquots were also assessed for the whole amount of the factor using a structural ELISA assay, which does not reflect the bioactivity of the protein. Throughout the time of observation, the concentrations of TGF $\beta 3$ were similar in SCM and SFM, and after 21 days of storage remained at 
$102 \pm 8 \%$ and $105 \pm 3 \%$ of the initial levels, respectively in SCM and in SFM. The measured structural presence of TGF $\beta 3$ excluded typical explanations for the loss of protein bioactivity, related to aggregation [8] or adsorption to the surface of the storage vessel [9]. The trend of a slightly higher stability of TGFß3 in SFM than in SCM ( $p=8.4 \mathrm{E}-06$ using ANOVA on all time points, with culture medium as a factor) could be due to the presence in serum of $\alpha$-Macroglobulin, which is known to bind to TGF $\beta$ and thereby form a latent complex [10].

In order to clarify the practical relevance of the bioactivity loss measured by the luciferase assay, samples of freshly prepared or stored TGF $\beta 3$ were assessed in a typical experimental system, namely for the proliferative effect on human articular chondrocytes in the presence of FGF-2 [5]. The reduction of the proliferative stimulus by serial dilutions of a freshly prepared sample starting from the concentration of $1 \mathrm{ng} / \mathrm{ml}$ first indicated the sensitivity of the assay, with a significant reduction (57 $\pm 19 \%, p=0.0043)$ in cell proliferation between 1 and $0.5 \mathrm{ng} / \mathrm{ml}$ (Fig. 3A). Samples of TGF $\beta 3$ stored for different times were then diluted to the nominal concentration of $1 \mathrm{ng} / \mathrm{ml}$ and assessed for their proliferative effect. The slight reduction of the cell proliferation rate in the presence of stored TGF $\beta 3$ as compared to the freshly prepared standard was consistent with the functional loss of $15-40 \%$ measured by the luciferase assay (Fig. 2B) and the dose-response curve in TGFß3-induced proliferation (Fig. 3A). Interestingly, however, such reduction was not statistically significant at any investigated storage time, indicating a negligible relevance of the TGF $\beta 3$ bioactivity loss in our experimental system. 


\section{Conclusions}

This study demonstrates a significant loss of TGF $\beta 3$ bioactivity during storage under typical conditions, which could not have been predicted using a conventional ELISA method. The fact that this loss did not significantly affect the biological readout in our investigated experimental setup (i.e., chondrocyte proliferation rate) supports the possibility of having TGF $\beta 3$ pre-supplemented in the proliferation medium for bioreactor-based chondrocyte expansion [11].

With the ultimate goal of defining suitable storage conditions of culture media in automated bioreactors for cell culture, the proposed approach and methods should be extended to assessing the stability of other possibly labile medium supplements.

\section{Acknowledgements}

We are garteful to Dr. D.B. Rifkin from the New York State University School of Medicine for his permission to work with tMLECs, Novartis Pharma AG for the donation of assay kit, Mr. K. Madörin for technical assistance with the assay and Prof. Dr. T. Arvinte for helpful discussions. 
[1] I. Martin, D. Wendt, M. Heberer, The role of bioreactors in tissue engineering, OsteoArthritis and Cartilage, 22, (2004), 80-86.

[2] D.A. Lawrence, Transforming Growth Factor- $\beta$ : a general review, Eur. Cytokine Netw, 7, (1996), 363-374.

[3] M. Dong, G.C. Blobe, Role of Transforming Growth factor- $\beta$ in Hematologic Malignancies, Blood 107 (2006), 4589-4596.

[4] B. Johnstone, T. M. Hering, A.I. Caplan, V.M. Goldberg, J.U. Yoo. In Vitro Chondrogenesis of Bone Marrow-Derived Mesenchymal Progenitor Cells, Experimental Cell Research 238 (1998), 265-272.

[5] M. Jakob, O. Démarteau, D. Schäfer, B. Hintermann, W. Dick, M. Heberer, I. Martin. Specific growth factors during the expansion and redifferentiation of adult human articular chondrocytes enhance chondrogenesis and cartilaginous tissue formation in vitro. Journal of Cellular Biochemistry 81 (2001), 368-377.

[6] M. Moretti, D. Wendt, S.C. Dickinson, T.J. Sims, A.P. Hollander, D.J. Kelly, P.J. Prendergast, I. Martin, Effects of in Vitro Preculture on in Vivo Development of Human Engineered Cartilage in an Ectopic Model, Tissue Eng. 9-10 (2005), 14211428.

[7] M. Abe, An Assay for Transforming Growth Factor-beta Using Cells Transfected with a Plasiminogen Activator Inhibitor-1 
Promotor-Luciferase Construct. Anal. Biochem., 212 (2)(1994), 276-284.

[8] J. Pellaud, U. Schote, T. Arvinte, J. Seelig, Conformation and Self-association of Human Recombinant Growth Factor-ß 3 in Aqueous Solutions. J.Biol.Chem., 274, (1999), 7699-7704.

[9] W. Wang, Instability, stabilization and formulation of liquid protein pharmaceuticals, Int. J. Pharmaceutics, 185, (1999), 129188.

[10] S. Arandjelovic, T.A. Freed, S.L. Gonias, Growth Factor-Binding Sequence in Human a2-Macroglobulin Targets the ReceptorBinding Site in Transforming Growth Factor- $\beta$, Biochemistry, 42, (2003) 6121-6127.

[11] S. E. Francioli, I. Martin, C. P. Sie, R. Hagg, R. Tommasini, C. Candrian, M. Heberer, A. Barbero. Growth Factors for ClinicalScale Expansion of Human Articular Chondrocytes: Relevance for Automated Bioreactor Systems, Tissue Engineering.13, 2007, $1227-1234$ 


\section{Figure legends}

Figure 1

Luciferase Assay Principle: Binding of TGFß3 to its receptor in mink lung epithelial cells transfected with a construct containing luciferase (tMLEC) induces a dose dependent increase of luciferase expression through the PAI-1 promoter. After adding the reagent Beetle Luciferin to the cell lysate, the emitted luminescence is acquired by use of a luminometer.

\section{Figure 2}

(A) Typical luminescence curves for the luciferase assay in the presence of different concentrations of TGF $\beta 3$. The residual bioactivity of stored TGF $\beta 3$ as compared to the freshly thawed standard was calculated from the shift between the parallel lines fitted through the two dilution curves. Error bars indicate standard deviations ( $\mathrm{n}=4$ independent data sets per experimental condition). (B) Bioactivity stability of TGF $\beta 3$ in serum containing medium or serum free medium. Bars indicate the measured bioactivity relative to a freshly thawed standard. Asterisks indicate a statistically significant difference from the corresponding condition (i.e., using the same medium) at day 1. Error bars indicate a confidence interval of 95\% ( $\mathrm{n}=3$ independent data sets per experimental condition).

\section{Figure 3}

Proliferation of human articular chondrocytes in the presence of TGF $\beta 3$ at different concentrations or storage times, assessed by [3H]-Thymidine 
incorporation and expressed as counts per minute (CPM). (A) Dilution series starting from $1 \mathrm{ng} / \mathrm{ml}$ TGF $\beta 3$ of a freshly prepared standard. The overhead bracket with asterisk indicates a statistically significant difference between groups ( $n=4$ independent data sets per experimental condition). (B) Proliferative effect of TGF $\beta 3$ following storage in SCM at $37^{\circ} \mathrm{C}$ for up to 21 days. Stored samples of $10 \mathrm{ng} / \mathrm{ml}$ TGF $\beta 3$ were diluted in fresh SCM to result in an intended final concentration of 1 ng/ml TGF $\beta 3$, a concentration typically applied for chondrocyte proliferation. Dashed lines indicate the expected range of cell proliferation for a freshly prepared standard, based on results presented in part (A). All values are presented as mean \pm standard deviation ( $\mathrm{n}=4$ independent data sets per experimental condition). 